\title{
The epidemiology of iodine deficiency disorders (IDD) in Yemen
}

\author{
AZ Zein ${ }^{\dagger}$, S Al-Haithamy ${ }^{1, *}$, Q Obadi $^{2}$ and S Noureddin ${ }^{3}$ \\ ${ }^{1}$ Health and Nutrition, UNICEF (Yemen), PO Box 5747, Grand Central Station, New York, NY 10163, USA: \\ ${ }^{2}$ Nutrition Department, Ministry of Public Health, P.O. Box 299, Sana'a, Yemen: \\ ${ }^{3}$ IDD consultant, 14 Rue Ibn, Al Haitam, Rabat, Morocco
}

Submitted 23 August 1999; Accepted 19 November 1999

\begin{abstract}
Objective: This first nationwide survey was undertaken to estimate the prevalence rates and severity of iodine deficiency disorders (IDD) and the proportion of households consuming iodized salt.

Design: The country was stratified into two ecological zones and 30 clusters (primary schools) from each zone, including the required numbers of pupils, were selected randomly. A subsample of pupils provided urine and salt samples for the determination of urinary iodine excretion (UIE) and presence of iodate, respectively. Setting: Yemen.

Subjects: There were a total of 2984 pupils aged 6-12 years of whom 2003 were boys and 981 girls. The majority (1800) pupils were from the lowland/coastal areas (zone II) and the rest (1184) from the mountainous regions (zone I).

Results: The total goitre rates (TGR) in the whole country, zones II and I were $16.8 \%$, $31.1 \%$ and $7.4 \%$, respectively. The TGR in zone I for males was $32.8 \%$ and $27.3 \%$ for females, while in zone II the corresponding rates were $8.1 \%$ and $5.9 \%$, respectively, and the differences were not statistically significant. Only three cases of visible goitres were encountered. The median UIE levels in zones I, II and the whole country were 13.6, 18.9 and $17.3 \mu \mathrm{g} \mathrm{dl}^{-1}$, respectively. Based on UIE cut-off points recommended by WHO, IDD was severe in $4.7 \%$ of pupils in zone I and $2.6 \%$ in zone II. Mild and moderate IDD were found in $18.5 \%$ and $8.7 \%$ of the pupils respectively. Nearly $70 \%$ of the surveyed pupils had UIE values of $\geqslant 10 \mu \mathrm{g} \mathrm{dl}^{-1}$ (no deficiency). Girls had relatively better iodine nutrition as suggested by higher levels of median UIE. In addition, across all age groups median UIE values were above $10 \mu \mathrm{g} \mathrm{dl}^{-1}$. Over half of the households consumed iodized salt.

Conclusions: Since the introduction of universal salt iodization in 1996 both the prevalence and severity of IDD in Yemen were reduced markedly and Yemen can now be classified as a country with a mild IDD problem. However, the low level of households consuming iodized salt may hamper the goal of IDD elimination.
\end{abstract}

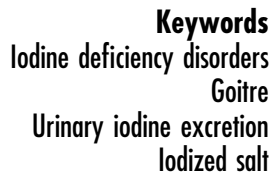

Before 1991, levels of IDD were not perceived by Yemeni health authorities to be a public health problem. The seminal and comprehensive national nutrition survey of the Yemen Arab Republic ${ }^{1}$ in 1979 did not address IDD or goitres as is customary in large-scale nutrition surveys, but a similar survey in the former South Yemen $^{2}$ in 1983 reported a TGR of $0.15 \%$ for that country. In $1991, \mathrm{WHO}^{3}$ conducted a rapid goitre survey in four governorates in the northern part of Yemen and reported a TGR of 32\% among school children which suggested that Yemen is a country with a severe IDD problem. Subsequently, in 1995, UNICEF, in collaboration with the Ministry of Public Health, launched a national IDD control programme with universal salt iodization as the major strategy to combat IDD.

Four years after the initiation of universal salt iodization, Yemen lacked data on the epidemiology of IDD. This survey was undertaken to rectify this deficiency and its results will assist the national IDD programme in establishing a baseline and to monitor progress towards the elimination of IDD.

\section{Objectives of the survey}

The objectives of the survey were to: (i) estimate the prevalence of goitres among pupils aged 6-12 years; (ii) determine the iodine nutritional status by measuring urinary iodine levels in a subsample of school children; and (iii) estimate the proportion of households consuming iodized salt.

\section{The setting}

The total land area of the Republic of Yemen, excluding the Al-Rub Al-Khali desert, is $555000 \mathrm{~km}^{2}$. Located in the southern part of the Arabian Peninsula, Yemen is bounded 
by the Arabian Sea and Gulf of Aden in the south, the Sultanate of Oman in the east, the Red Sea in the west and the Kingdom of Saudi Arabia in the north.

Yemen is divided into three broad natural regions, each with unique topographical and climate conditions ${ }^{4}$. These are, firstly, the mountains and highlands which cover $60 \%$ of the total landmass. The highland region comprises the north-south mountain range running parallel to the Red Sea coast down to the Bab al Mandab Strait in the far south, and the east-west range, running parallel to the Gulf of Aden coast up to Oman. Secondly, there are the coastal plains, which extend over $2500 \mathrm{~km}$ from north to south along the Red Sea and from west to east along the Gulf of Aden and the Arabian Sea. Thirdly, there are the eastern plains comprising around 15\% of Yemen's total land area; these extend along the eastern and northern L-shaped massif running from north to south and then eastward all the way to Saudi Arabia and Oman.

The population of Yemen was projected to be 17 million $^{5}$ in 1998 . With a total fertility rate of seven live births and an annual growth rate of 3.5\%, it is one of the fastest growing populations in the Arabian Peninsula. Infant mortality rates (83 per 1000 live births) and child mortality rates (102 per 1000 live births) are also among the highest in the region ${ }^{6}$. Yemen is one of the poorest countries of the world, measured not only by its US $\$ 270$ per capita GNP in 1997, but also in almost every measure of quality of life $\mathrm{e}^{7}$.

\section{Materials and methods}

\section{Sampling}

Although the country has three distinct ecological zones, it was divided in two ecological zones to reflect the distribution of IDD and simplify logistics. Zone I was the mountainous governorates or districts with an estimated TGR of $32 \%$ determined from a previous rapid assessment survey $^{3}$ in four governorates of this area. The zone comprises approximately 80\% of Yemen's estimated 17 million population ${ }^{5}$. Zone II is the submountainous and lowland governorates/districts with an estimated maximum goitre prevalence of $10 \%$.

The sample size $(n)$ for each ecological zone was calculated according to the following formula using EPIINFO software, version $6.04 \mathrm{~b}$ (Centre for Disease Control and Prevention, Atlanta):

$$
n=2 * \frac{Z^{2} P(1-P)}{d^{2}}
$$

where $Z=95 \%$ confidence level, $P=$ estimated prevalence, $2=$ design effect and $d=$ absolute precision. A precision of $4 \%$ in zone I and $2 \%$ in zone II, and prevalence rates of goitres of $30 \%$ and $10 \%$ in zones I and II, respectively, were the computational assumptions. Accordingly, the sample size for zones I and II was calculated to be 1170 and 1800 children, respectively. The survey protocol which was later reviewed by an external consultant, sampling, supervision of fieldwork, data entry, analysis and report writing was done by UNICEF Yemen health and nutrition officers while the organization and management of the actual fieldwork was done by staff of the Ministry of Public Health.

Data handling and analyses were done using the EPIINFO package. Descriptive statistics were computed using this software as were the chi-square test for differences between proportions and the one-way analysis of variance ( $F$ statistics) for testing differences between means. The association between a risk factor and disease was tested by generating odds ratios (OR) and the associated 95\% confidence intervals (CI). The difference between two medians was tested manually using a nonparametric method, the median test ${ }^{8}$.

The 95\% CI for the percentage of goitre and household iodized salt consumption were computed using the EPITABLE module of EPIINFO, which uses the fleiss quadratic method. This approach takes into account both the design effect and the cluster sampling methodology. Sensitivity and specificity analyses were also done using the EPIINFO software to test the value of goitre palpation versus UIE, the 'gold standard' as an instrument for screening IDD in field conditions.

Thirty clusters were selected randomly from each zone. From each cluster (a primary school) the required number of school children were selected by a systematic random sampling method. In each school one or more classes (grades 1-6), depending on the calculated sample size and number of pupils attending that class, was then selected randomly. Based on the sample size calculated above, 39 children were examined for goitre in each school in zone I and 60 children in each school in zone II. In three sites, where a school did not have the required number of pupils, an adjacent school was used for replacement.

\section{Goitre palpation}

Goitre palpation was performed by two teams of physicians who had undergone training on goitre palpation by a physician with considerable experience in conducting IDD surveys. Goitre classification was according to a simplified recommendation ${ }^{9}$. The sum of grades 1 and 2 provided the TGR. Assessment of the severity of IDD was based on the TGR and UIE. The following TGR values were used for the determination of IDD severity: 5.0$19.9 \%=$ mild, $20.0-29.9 \%=$ moderate, and $30.0 \%$ or more $=$ severe $^{9}$.

\section{Urinary iodine excretion}

Casual urine samples were collected from a random subsample of 390 and 600 children from zones I and II, respectively. Urine samples were collected in $1 \mathrm{ml}$ plastic bottles with screw caps. The samples were stored in 
refrigerators until shipment to the medical chemistry laboratory of the Faculty of Medicine and Pharmacy of Rabat, Morocco, for analysis according to method A described by Dunn et al. ${ }^{10}$ with the results expressed in $\mu \mathrm{g} \mathrm{dl}^{-1}$. In this laboratory, quality control was performed by distributing two urine pools through series of samples to serve as an internal control and the results were expressed as percent coefficient of variation (CV\%).

Classification of the severity of IDD was according to the cut-off points of UIE values ${ }^{9}$; thus, urinary iodine values $\left(\mu \mathrm{g} \mathrm{dl}^{-1}\right)<2=$ severe, $2-4.9=$ moderate, $5-9.9=$ mild and $\geqslant 10=$ no deficiency.

\section{Iodine content of salt consumed at the bousebold level}

In each school 20 salt samples, about $20 \mathrm{~g}$ of salt each, were collected by requesting pupils to bring salt samples from their respective homes. The samples were from routinely consumed salt. Each sample was tested on the spot for the presence of iodate using a rapid test kit (MBI KITS, Madras, India).

\section{Results}

In comparison to the sample size suggested by the calculation exercise during the planning phase of the survey (2870), a total of 2984 pupils participated in the study in both geographic zones, suggesting an optimum survey coverage rate.

\section{Demographic characteristics of the survey population}

The age and sex distribution of the survey population by geographic zones is shown in Table 1. The total number of surveyed pupils was 2984; the majority (1800) were from zone II and the rest (1184) from zone I. The sex ratio $(\mathrm{M}: \mathrm{F})$ was $1: 2$ in both zones, indicating the preponderance of males. The percentage of males in zones I and II were $68.5 \%$ and $66.2 \%$, respectively, while the corresponding percentages for females were $31.5 \%$ and $33.8 \%$.
However, there were no statistically significant differences in these percentages (Table 1).

The greatest number of pupils were aged 8 years in the highland zones and in the overall survey sample, but were aged 9 years in zone II. Pupils aged 9 years old and below comprised $64 \%$ of the survey sample. In both zones, the median age was 9 years and was therefore identical.

\section{Prevalence rates and severity of goitres}

Of the total 2984 pupils palpated for goitres in the two zones, there were 501 grade 1 and grade 2 goitres (Table 2), resulting in an over all TGR of $16.8 \%$ (CI 16.520.5) for the whole country, 31.1\% (CI 27.4-35.0) in zone I and only 7.4\% (CI 5.8-9.3) in zone II. Except for zone I where rates of IDD are severe (TGR $\geqslant 30 \%$ ), zone II and the whole country can be classified as having a mild IDD problem.

The prevalence rates of zero grade goitres in zones I and II were $68.9 \%$ and $92.6 \%$, respectively, while the corresponding total rates of grade 1 goitres in these zones were $30.8 \%$ and $7.4 \%$, respectively, indicating a four-fold occurrence of goitres in the highland mountainous zone. Grade 2 goitres were encountered only in zone I and with a low prevalence rate of $0.3 \%$.

The age-specific prevalence rates of goitres by grades and zones are shown in Table 2. Age-specific grade 1 goitre rates in zone II varied between $28.1 \%$ and $34.2 \%$ across all age groups, with a peak prevalence rate among 10 -year-old pupils. In zone II, age-specific grade 1 goitre rates were consistently lower in comparison with zone 1 , varying between $3.6 \%$ among 6-year-old pupils to a maximum of $10.5 \%$ among 8 -year-old pupils.

The prevalence rates of goitres by gender are shown in Table 3 . Since the number of grade 2 goitres is very small, all such goitres were combined with grade 1 for the purpose of this analysis. Accordingly, the sex-specific prevalence rates of male goitres exceeded those of females irrespective of zones. In zone I the TGR of males and females were $32.8 \%$ and $27.3 \%$, respectively, while in zone II the corresponding rates were $8.1 \%$ and $5.9 \%$.

Table 1 Percentage distribution of pupils by age, sex and zones

\begin{tabular}{|c|c|c|c|c|c|c|c|c|c|}
\hline \multirow[b]{2}{*}{ Age (years) } & \multicolumn{3}{|c|}{ Zone I } & \multicolumn{3}{|c|}{ Zone II } & \multicolumn{3}{|c|}{ All zones } \\
\hline & $\begin{array}{c}\text { Male } \\
(n=811) \\
(\%)^{*}\end{array}$ & $\begin{array}{c}\text { Female } \\
(n=373) \\
(\%) \dagger\end{array}$ & $\begin{array}{c}\text { Total } \\
(n=1184) \\
(\%)\end{array}$ & $\begin{array}{c}\text { Male } \\
(n=1192) \\
(\%)^{*}\end{array}$ & $\begin{array}{c}\text { Female } \\
(n=608) \\
(\%) \dagger\end{array}$ & $\begin{array}{c}\text { Total } \\
(n=1800) \\
(\%)\end{array}$ & $\begin{array}{c}\text { Male } \\
(n=2003) \\
(\%)\end{array}$ & $\begin{array}{c}\text { Female } \\
(n=981) \\
(\%)\end{array}$ & $\begin{array}{c}\text { Total } \\
(n=2984) \\
(\%)\end{array}$ \\
\hline 6 & 5.9 & 10.4 & 7.3 & 9.9 & 12.6 & 10.9 & 8.3 & 11.8 & 9.4 \\
\hline 7 & 16.5 & 16.6 & 16.5 & 18.7 & 17.4 & 18.3 & 17.8 & 17.1 & 17.6 \\
\hline 8 & 19.9 & 21.4 & 20.4 & 17.7 & 18.2 & 17.9 & 18.6 & 19.4 & 18.9 \\
\hline 9 & 17.5 & 17.1 & 17.4 & 15.9 & 23.2 & 18.4 & 16.5 & 20.9 & 18.0 \\
\hline 10 & 15.7 & 16.6 & 16.0 & 15.1 & 18.4 & 16.3 & 15.4 & 17.7 & 16.2 \\
\hline 11 & 11.3 & 8.8 & 10.5 & 14.4 & 6.9 & 11.9 & 13.1 & 7.6 & 11.3 \\
\hline 12 & 12.9 & 8.8 & 11.6 & 7.8 & 3.1 & 6.3 & 9.9 & 5.3 & 8.4 \\
\hline Total & 100.0 & 100.0 & 100.0 & 100.0 & 100.0 & 100.0 & 100.0 & 100.0 & 100.0 \\
\hline
\end{tabular}

${ }^{*}$ Differences between the percentage of males in both zones, NS $\left(\chi^{2}=2.01\right.$; d.f. $\left.=1 ; P=0.15\right)$.

†Differences between the percentage of females in both zones, NS $\left(\chi^{2}=2.51\right.$; d.f. $\left.=1 ; P=0.11\right)$. 
Table 2 Age-specific goitre (grade 1 or 2) prevalence rates by zone

\begin{tabular}{|c|c|c|c|c|c|c|c|c|}
\hline \multirow{3}{*}{$\begin{array}{l}\text { Age } \\
\text { (years) }\end{array}$} & \multicolumn{5}{|c|}{ Zone 1} & \multicolumn{3}{|c|}{ Zone II } \\
\hline & \multirow{2}{*}{$\begin{array}{c}\text { No. } \\
\text { examined }\end{array}$} & \multicolumn{2}{|c|}{ Grade 1} & \multicolumn{2}{|c|}{ Grade 2} & \multirow{2}{*}{$\begin{array}{c}\text { No. } \\
\text { examined }\end{array}$} & \multicolumn{2}{|c|}{ Grade 1} \\
\hline & & No. & Per cent & No. & Per cent & & No. & Per cent \\
\hline 6 & 87 & 25 & 28.7 & 0 & 0.0 & 196 & 7 & 3.6 \\
\hline 7 & 196 & 59 & 30.1 & 1 & 0.5 & 330 & 25 & 7.6 \\
\hline 8 & 242 & 68 & 28.1 & 1 & 0.4 & 323 & 34 & 10.5 \\
\hline 9 & 206 & 64 & 31.1 & 0 & 0.0 & 331 & 21 & 6.3 \\
\hline 10 & 190 & 65 & 34.2 & 0 & 0.0 & 293 & 21 & 7.2 \\
\hline 11 & 125 & 38 & 30.4 & 1 & 0.8 & 214 & 13 & 6.1 \\
\hline 12 & 138 & 46 & 33.3 & 0 & 0.0 & 113 & 12 & 9.0 \\
\hline Total & 1184 & 365 & $30.8^{*}$ & 3 & $0.3^{*}$ & 1800 & 133 & $7.4^{*}$ \\
\hline
\end{tabular}

${ }^{*}$ Difference between the TGR rate of zone I and II is statistically highly significant $\left(\chi^{2}=286.96\right.$; d.f. $\left.=1 ; P=0.0001\right)$.

Table 3 Total goitre rates by zones and gender

\begin{tabular}{|c|c|c|c|c|c|c|c|c|c|}
\hline \multirow[b]{2}{*}{ Gender } & \multicolumn{3}{|c|}{ Zone I* } & \multicolumn{3}{|c|}{ Zone II† } & \multicolumn{3}{|c|}{ All zonesł } \\
\hline & $\begin{array}{c}\text { No. } \\
\text { examined }\end{array}$ & $\begin{array}{l}\text { No. with } \\
\text { goitre }\end{array}$ & Per cent & $\begin{array}{c}\text { No. } \\
\text { examined }\end{array}$ & $\begin{array}{l}\text { No. with } \\
\text { goitre }\end{array}$ & Per cent & $\begin{array}{c}\text { No. } \\
\text { examined }\end{array}$ & $\begin{array}{l}\text { No. with } \\
\text { goitre }\end{array}$ & Per cent \\
\hline $\begin{array}{l}\text { Male } \\
\text { Female }\end{array}$ & $\begin{array}{l}811 \\
373\end{array}$ & $\begin{array}{l}266 \\
102\end{array}$ & $\begin{array}{l}32.8 \\
27.3\end{array}$ & $\begin{array}{r}1192 \\
608\end{array}$ & $\begin{array}{l}97 \\
36\end{array}$ & $\begin{array}{l}8.1 \\
5.9\end{array}$ & $\begin{array}{r}2003 \\
981\end{array}$ & $\begin{array}{l}363 \\
138\end{array}$ & $\begin{array}{l}18.1 \\
14.1\end{array}$ \\
\hline Total & 1184 & 368 & 31.1 & 1800 & 133 & 7.4 & 2984 & 501 & 16.8 \\
\hline
\end{tabular}

${ }^{*}$ Difference within zone I, NS $\left(\chi^{2}=3.55 ;\right.$ d.f. $\left.=1 ; P=0.059\right)$. Risk of having goitres among boys in zone I, NS $\left(\mathrm{OR}=1.3 ; 95 \% \mathrm{Cl} 0.98-1.722 ; \chi^{2}=3.54 ; P=0.059\right)$. †Difference within zone II, NS $\left(\chi^{2}=2.89 ;\right.$ d.f. $\left.=1 ; P=0.89\right)$. Risk of having goitres among boys in zone II, NS $\left(\mathrm{OR}=1.41 ; 95 \% \mathrm{Cl} 0.93-2.13 ; \chi^{2}=2.89 ; P=0.08\right)$. †Difference between zones I and II, highly significant $\left(\chi^{2}=7.75\right.$; d.f. $\left.=1 ; P=0.005\right)$.

The differences in sex-specific goitre prevalence rates were statistically highly significant only when data for both zones were pooled, while there were no statistically significant differences in these rates in zone I. Further analysis was made to establish the association between goitres and gender. In zone I the risk of having goitre was 1.3 times greater for boys compared with girls, and in zone II this risk was 1.41 times greater for boys. These associations were not statistically significant (Table 3).

\section{Urinary iodine excretion}

The number of pupils who provided urine samples in zone I, zone II and the combined zones were 408, 602 and 1010, respectively. These figures reflect the systematic sampling (one in three) of pupils for obtaining urine samples. Of these, 974 (96.4\%) were available for the determination of urinary iodine. The internal quality control of urine samples resulted in a CV\% of 12 and 9 for pools at 6.4 and $28.0 \mu \mathrm{g} \mathrm{dl}^{-1}$, respectively. Table 4 shows median UIE values by age and zone. In zone I the lowest median UIE values were observed among 7, 10 and 11 year olds and the highest at 12 years of age. In zone II median UIE values were less variable. Relatively higher median values of urinary iodine were observed in zone II and the difference between the zones is statistically significant (Table 4). Furthermore, in each zone there were cases whose urinary iodine concentration were very high, equivalent to eight times the median level for each zone.

Table 5 depicts median and centile UIE values by gender and zone. In both zones and the whole country, the median urinary iodine concentration values of females

Table 4 Median urinary concentration of iodine $\left(\mu \mathrm{g} \mathrm{dl}^{-1}\right)$ for pupils by age and zones

\begin{tabular}{|c|c|c|c|c|c|c|}
\hline \multirow[b]{2}{*}{ Age (years) } & \multicolumn{2}{|c|}{ Zone I } & \multicolumn{2}{|c|}{ Zone II } & \multicolumn{2}{|c|}{ All zones } \\
\hline & No. examined & Median UIE & No. examined & Median UIE & No. examined & Median UIE \\
\hline 6 & 31 & 16.3 & 65 & 19.6 & 96 & 19.2 \\
\hline 7 & 63 & 11.6 & 96 & 17.5 & 159 & 16.0 \\
\hline 8 & 83 & 12.7 & 104 & 18.4 & 187 & 14.6 \\
\hline 9 & 63 & 13.6 & 114 & 18.7 & 177 & 16.5 \\
\hline 10 & 62 & 11.1 & 99 & 19.7 & 161 & 18.9 \\
\hline 11 & 39 & 11.6 & 69 & 19.3 & 108 & 12.8 \\
\hline 12 & 46 & 22.4 & 40 & 19.9 & 86 & 21.4 \\
\hline Total & 387 & $13.6^{*}$ & 587 & $18.9^{*}$ & 974 & 17.3 \\
\hline
\end{tabular}

*Median test significant: $\chi^{2}=24.5$; d.f. $=1 ; P<0.001$. 
Table 5 Median and centile urinary concentration of urine $\left(\mu \mathrm{g} \mathrm{dl}^{-1}\right)$ values by gender and zones

\begin{tabular}{|c|c|c|c|c|c|c|c|c|c|}
\hline \multirow[b]{2}{*}{ Gender } & \multicolumn{3}{|c|}{ Zone I } & \multicolumn{3}{|c|}{ Zone II } & \multicolumn{3}{|c|}{ All zones } \\
\hline & 5th centile & Median & 95th centile & 5th centile & Median & 95th centile & 5th centile & Median & 95th centile \\
\hline Male & 2.12 & $12.9^{*}$ & 48.02 & 3.40 & $18.4 \dagger$ & 64.27 & 2.59 & $16.3 \ddagger$ & 57.02 \\
\hline Female & 2.25 & $15.2^{*}$ & 75.20 & 3.02 & $20.4 \dagger$ & 56.3 & 2.48 & $18.6 \ddagger$ & 65.28 \\
\hline
\end{tabular}

${ }^{*} \chi^{2}=0.018 ; P>0.05 ; \mathrm{NS}$

$\mathrm{t} \chi^{2}=0.07 ; P>0.05 ; \mathrm{NS}$.

$\ddagger \chi^{2}=0.05 ; P>0.05 ;$ NS.

Table 6 Severity of IDD by urinary lodine concentration levels

\begin{tabular}{|c|c|c|c|c|c|c|}
\hline \multirow[b]{2}{*}{ Severity } & \multicolumn{2}{|c|}{ Zone I } & \multicolumn{2}{|c|}{ Zone II } & \multicolumn{2}{|c|}{ All zones } \\
\hline & No. examined & Per cent & No. examined & Per cent & No. examined & Per cent \\
\hline $\begin{array}{l}\text { Severe }\left(<2 \mu \mathrm{g} \mathrm{dl}^{-1}\right) \\
\text { Moderate }\left(2-4.9 \mu \mathrm{g} \mathrm{dl}^{-1}\right) \\
\text { Mild }\left(5-5.9 \mu \mathrm{g} \mathrm{dl}^{-1}\right) \\
\text { No deficiency }\left(\geqslant 10 \mu \mathrm{g} \mathrm{dl}^{-1}\right)\end{array}$ & $\begin{array}{r}18 \\
47 \\
82 \\
240\end{array}$ & $\begin{array}{l}4.7^{\star} \\
12.1 \dagger \\
21.2 \ddagger \\
62.0\end{array}$ & $\begin{array}{r}15 \\
38 \\
98 \\
436\end{array}$ & $\begin{array}{l}2.6^{*} \\
6.5 \dagger \\
16.7 \ddagger \\
74.3\end{array}$ & $\begin{array}{r}33 \\
85 \\
180 \\
676\end{array}$ & $\begin{array}{r}3.4 \\
8.7 \\
18.5 \\
69.4\end{array}$ \\
\hline Total & 387 & 100.0 & 587 & 100.0 & 974 & 100.0 \\
\hline
\end{tabular}

${ }^{*} \chi^{2}($ Yates corrected $)=2.06 ; P=0.15 ; \mathrm{NS}$.

$\mathrm{t} \chi^{2}($ Yates corrected $)=0.72 ; P=0.39 ;$ NS.

$\ddagger \chi^{2}=0.58 ;$ d.f. $=1 ; P=0.44$; NS.

were greater than those of males. However, the differences in the median values were not statistically significant (Table 5). The median urinary iodine concentration levels in zones I, II and the whole country were 13.6, 18.9 and $17.3 \mu \mathrm{g} \mathrm{dl}^{-1}$, respectively. Since these values are above $10 \mu \mathrm{g} \mathrm{dl}^{-1}$, the cut-off point for no IDD, it can prima facie be generalized that IDD is no longer a public health problem in Yemen. However, further data analysis (Table 6) revealed that this conclusion is not yet warranted as $30.6 \%$ of the pupils had mild, moderate or severe IDD.

The TGR value in zone I $(>30 \%)$ suggested a severe IDD problem in this area, but only a mild IDD problem in zone II and the whole country. In contrast, the UIE values indicated that only $4.7 \%$ of pupils in zone I, $2.6 \%$ in zone II and $3.4 \%$ in the whole country had severe IDD. Both moderate and mild IDD levels are also greater in zone I. Over all, nearly $70 \%$ of the survey population was replete with iodine, while $18.5 \%$ had mild, $8.7 \%$ had moderate and $3.4 \%$ had severe IDD. When tested statistically, the rates of severity of IDD (mild, moderate and severe) did not differ significantly between the two zones (Table 6). However,

Table 7 Sensitivity and specificity of goitre palpation versus urinary iodine excretion

\begin{tabular}{llll}
\hline & \multicolumn{2}{c}{ Urinary iodine level $\left(\mu \mathrm{g} \mathrm{dl}^{-1}\right)$} & \\
\cline { 2 - 3 } Goitre & \multicolumn{1}{c}{$\geqslant 10$} & Total \\
\hline Present & $76(25.5 \%)^{*}$ & $122(18.0 \%) \ddagger$ & 198 \\
Absent & $222(74.5 \%) \dagger$ & $554(81.9 \%) \S$ & 776 \\
Total & 298 & 676 & 974 \\
\hline
\end{tabular}

*TP (true positive, sensitivity).

†FN (false negative).

IFP (false positive).

$\S T N$ (true negative, specificity). the rates of 'no deficiency' are relatively higher in zone II and are statistically significant. The extent of the discrepancy between data on goitre palpation and urinary iodine concentration was analysed by subjecting data on these parameters to sensitivity and specificity analysis by using urinary excretion data (Table 7).

From data in Table 7 the sensitivity and specificity of goitre palpation were $25.5 \%$ and $81.9 \%$, respectively. The associated positive and negative predictive values of the test were $38 \%$ and $71.4 \%$, respectively. Clearly goitre palpation is associated with low sensitivity.

\section{Housebold iodized salt consumption}

Although all pupils were asked to bring salt samples from their homes for testing, 222 (18.7\%) pupils in zone I, 900 (50\%) in zone II and 1122 (37.6\%) for the entire study population did not provide salt samples. The salt samples brought for analysis were ground, sea and rock. Only sea and ground salts were iodized.

The proportion of households consuming iodized salt is $54.1 \%$ for the whole country (Table 8). If the design effect for the cluster sampling used in this study is taken into account the 95\%CI around this percentage is 50.2-57.8\% which is the range or interval of estimates for the unknown true values of the proportion of households consuming iodized salt. The proportion of households consuming iodized salt in both zones is similar.

\section{Discussion}

The survey teams had to contend with several operational and logistical problems. The major problems encountered were lack of security in remote areas, reluctance of older girls (10-12 years of age) to undergo goitre palpation due 
Table 8 Proportion of households consuming iodized salt

\begin{tabular}{|c|c|c|c|c|c|c|}
\hline \multirow[b]{2}{*}{ lodine present } & \multicolumn{2}{|c|}{ Zone I } & \multicolumn{2}{|c|}{ Zone II } & \multicolumn{2}{|c|}{ All zones } \\
\hline & No. & Per cent $(95 \% \mathrm{Cl})$ & No. & Per cent $(95 \% \mathrm{Cl})$ & No. & Per cent $(95 \% \mathrm{Cl})$ \\
\hline $\begin{array}{l}\text { Yes } \\
\text { No }\end{array}$ & $\begin{array}{l}340 \\
310\end{array}$ & $\begin{array}{l}52.3^{*}(46.7-57.8) \\
47.7\end{array}$ & $\begin{array}{l}400 \\
318\end{array}$ & $\begin{array}{l}55.7^{*}(50.3-60.9) \\
44.3\end{array}$ & $\begin{array}{l}740 \\
628\end{array}$ & $\begin{array}{l}54.1(50.2-57.8) \\
45.9\end{array}$ \\
\hline Total & 650 & 100.0 & 718 & 100.0 & 1368 & 100.0 \\
\hline
\end{tabular}

${ }^{*} \chi^{2}=0.85 ;$ d.f. $=1 ; P=0.35 ;$ NS.

to religious and cultural factors, the demand of some communities for survey teams to provide direct medical care, and lack of communication between survey teams and supervisors. Some of these problems, such as the inclusion of female physicians on the team as well as the provision of medical care, should be addressed in any future epidemiological surveys in Yemen. The provision of mobile telecommunication equipment to survey teams greatly facilitated work in the latter part of the survey. In general the survey was acceptable to the study population both in terms of undergoing goitre palpation and provision of urine samples. At a unit cost of US\$9.4 per child, the survey has been reasonably cost-effective. If future surveys use only UIE and determination of iodine salt samples, the unit cost will be reduced markedly.

That the prevalence rates of goitres in zone I were greater than those in zone II is not surprising as zone I is mountainous and a previous survey has documented very high goitre rates in this zone ${ }^{3}$. Although goitre prevalence rates in zone II were lower than in zone I, the magnitude of the goitre prevalence rate is more than expected. An earlier survey ${ }^{2}$ in parts of this zone reported a very low goitre prevalence rate of $0.15 \%$.

A TGR of $16.8 \%$ for the whole country found in this survey is half of the TGR reported for Yemen previously ${ }^{3}$. Based on TGR alone, zone I is an area where IDD still constitutes a severe public health problem. However two other indicators - a UIE level above $10 \mu \mathrm{g} \mathrm{dl}^{-1}$ in all ages and sexes and $70 \%$ of children excreting $\geqslant 10 \mu \mathrm{g} \mathrm{dl}^{-1}$ iodine (thus exceeding the recommended value of $50 \%$ as the core indicator ${ }^{9}$ for monitoring progress towards IDD elimination) - provide unequivocal evidence of the rapid progress made in Yemen towards elimination of IDD in a period of just 30 months following the introduction of universal salt iodization.

A potential bias that might explain the decline of IDD

Table 9 Association of gender with submission of urine samples

\begin{tabular}{|c|c|c|c|c|}
\hline \multirow[b]{2}{*}{ Gender } & \multicolumn{2}{|c|}{ Zone I samples* } & \multicolumn{2}{|c|}{ Zone II samples† } \\
\hline & Yes & No & Yes & No \\
\hline $\begin{array}{l}\text { Male } \\
\text { Female }\end{array}$ & $\begin{array}{l}138 \\
270\end{array}$ & $\begin{array}{l}235 \\
541\end{array}$ & $\begin{array}{l}187 \\
415\end{array}$ & $\begin{array}{l}421 \\
777\end{array}$ \\
\hline Total & 408 & 776 & 602 & 1198 \\
\hline
\end{tabular}

${ }^{*} \chi^{2}=1.55 ; P=0.21 ;$ NS.

$+\chi^{2}=2.98 ; P=0.08 ; \mathrm{NS}$. prevalence and severity since 1991 could have been the status of subjects who did not provide urine samples. Comparison of the gender and mean age frequencies of the two groups (Tables 9 and 10) did not reveal any differences. In addition, the differences in both goitre prevalence and UIE values observed in the two zones are chiefly attributable to altitude as the two areas are comparable in all other aspects. Similarly, there were no differences between these areas in the proportion of households consuming iodized salt nor in the distribution of age and gender of the survey population.

The rapid assessment survey ${ }^{3}$ in 1991 reported goitre prevalence rates between $60 \%$ and $100 \%$ with many visible goitres. This picture has changed dramatically as only three visible goitres were encountered in this survey, and iodine nutrition is adequate across all ages and among sexes, indicating that IDD in Yemen is no longer a severe public health problem but a mild one. This is due to the initiation of a salt iodization programme in 1996, which was conceptualized in 1993 by $\mathrm{UNICEF}^{14}$. As part of the strategy of universal salt iodization, the government passed its salt iodization legislation ${ }^{15}$ in 1996, but legal enforcement did not take place until October 1997. In addition, advocacy, social mobilization, training, monitoring and quality control were initiated.

At the factory level, over $90 \%$ of salt produced in Yemen is iodized. Between 1996 and 1998 a total of 119 million kg of iodized salt with potassium iodate was produced ${ }^{21}$, enough to provide each Yemeni with an average of $7 \mathrm{~g}$ of iodized salt per day. In the present survey, the percentage of households who consumed iodized salt approached $60 \%$, this is nearly a three-fold increase over the rate of $22 \%$ reported in $1996^{5}$. However, it is recommended to repeat household salt consumption surveys as the nonresponse rate for salt samples was 37.6\%.

Compared with males, both goitre prevalence rates and

Table 10 Comparison of mean age in years of pupils by urine sample submission status

\begin{tabular}{llllll}
\hline & \multicolumn{2}{c}{ Zone I samples $^{*}$} & & \multicolumn{2}{c}{ Zone II samples } \\
\cline { 2 - 3 } & $\begin{array}{c}\text { Yes } \\
(n=408)\end{array}$ & $\begin{array}{c}\text { No } \\
(n=776)\end{array}$ & & $\begin{array}{c}\text { Yes } \\
(n=602)\end{array}$ & $\begin{array}{c}\text { No } \\
(n=1198)\end{array}$ \\
\hline Mean $\pm S D$ & $8.9 \pm 1.79$ & $8.9 \pm 1.77$ & $8.7 \pm 1.74$ & $8.6 \pm 1.73$ \\
\hline${ }^{*} \mathrm{~F}=1.008 ; P=0.31 ;$ NS. & & & \\
$\dagger \mathrm{F}=0.14 ; P=0.71 ;$ NS. & & & &
\end{tabular}


median UIE values are lower for females for no apparent reasons. The fact that twice as many males as females were represented in the study is a reflection of the problem of access for girls to education and is related to sociocultural factors. It has been reported that the primary school enrolment rate for males was $70.7 \%$ while only $37.4 \%$ for females, with a national average of $55.0 \%{ }^{4}$. It has also been recommended that if the proportion of children attending school is less than $50 \%$, spot surveys should be done on two groups of children of the same age (i.e. those who attend school and those who do not) to ascertain if there is any significant difference between the two ${ }^{9}$. In view of the school enrolment rate prevalent in Yemen the recommendation to undertake two separate studies was not necessary.

With regard to the high prevalence rate of goitres (30.8\% in zone I), more credence should be given to the results of UIE levels rather than goitre palpation as the latter was associated with low sensitivity (25\%). UIE values indicated that the severity of IDD in zone I was only $4.7 \%$ compared with $>30 \%$ suggested by the goitre prevalence rates. In addition, as an IDD prevention programme progresses, goitre rates become progressively less useful, and urinary iodine levels progressively more useful, as elimination criteria ${ }^{9}$. Under field conditions rates of UIE are the best indicators to assess iodine deficiency as they significantly correlate with TGR and thyroid volume ${ }^{11}$.

Clusters associated with severe IDD in Yemen were traced to the mountainous areas of Sana'a, Hodeida, Dhamar, Shabwa and Abyan governorates. As the methodology employed in this survey does not permit the identification of hyperendemic areas, lot quality assurance sampling (LQAS) is the recommended method ${ }^{9}$.

Comparison of the epidemiological findings of this survey with similar ones is fraught with problems, as survey methodologies are not uniform, particularly in the selection of age groups. It has been recommended to include pupils between 6 and 12 years of age in IDD surveys ${ }^{9}$; however, many surveys still use pupils aged between 8 and 10 years ${ }^{14-16}$. For the sake of comparison, if this survey had adopted a similar age range the TGR would be $30.7 \%$ in zone I with a median UIE of $12.9 \mu \mathrm{g} \mathrm{dl}^{-1}, 8.0 \%$ in zone II with a median UIE of $18.9 \mu \mathrm{g} \mathrm{dl}^{-1}$, and for the whole country the TGR would be $16.8 \%$ with a median UIE of $16.5 \mu \mathrm{g} \mathrm{dl}^{-1}$. These figures indicate a close agreement of TGR and UIE data to those found when a 6-12-year age group is used. Therefore, for economic reasons 8-10-yearold pupils should be sampled in future IDD surveys in Yemen.

As well as the problem of lack of uniformity in the selection of target age groups for IDD surveys, many surveys in the Middle East were carried out in the early 1990s. For example, large- and small-scale surveys were conducted in Egypt, Iran, Iraq, Morocco, Sudan, Syria and Tunisia ${ }^{15}$ between 1990 and 1993. In recent years, Oman ${ }^{18}$, Lebanon ${ }^{17}$ and the West Bank and Gaza Strip ${ }^{13}$ have conducted surveys for the first time or to update previous ones. As the territories of Yemen, Oman and Saudi Arabia are geographically contiguous, data from these countries on IDD is of particular interest. In Oman a 1995 IDD survey among 8-11-year-old pupils reported a median UIE level of $9-10 \mu \mathrm{g} \mathrm{dl}^{-1}$ which suggested a mild IDD problem $^{18}$, while in the Gizan area in south-western Saudi Arabia, goitre prevalence was reported to be $2.7 \%$ among school pupils and urinary iodine was $>10 \mu \mathrm{g} \mathrm{dl}^{-1}$ in $78.8 \%$ of the surveyed pupils ${ }^{19}$.

In our survey some subjects excreted iodine up to eight times the median value of the entire study population. Some physicians in Yemen have expressed concern about excessive iodine-induced hyperthyroidism (IIH). Among the recommendations of the ICCIDD ${ }^{20}$ on IIH, two are very pertinent to Yemen:

1. Particular efforts towards early diagnosis should be made in subjects with multinodular goitre presenting with symptoms compatible with but not necessarily diagnostic of hyperthyroidism, because early diagnosis and treatment offers the best opportunity to avoid the serious complications, particularly those on the cardiovascular system. Heightened awareness on the part of the health sector will promote early detection of IIH.

2. All programmes of intervention with iodine should be carefully monitored for quality control of the vehicle and its biological impact. Monitoring offers the best opportunity for assessing the risk of IIH as well as the effectiveness of iodine deficiency prevention.

Three critical areas for the elimination of IDD in Yemen are sustaining iodized salt production and increasing the demand for it, strengthening monitoring and evaluation, and continuous public education. In addition, strategies must be developed to address the problem of severe IDD in areas where they occur.

\section{Acknowledgements}

This survey, including the entire universal salt iodization programme in Yemen, is fully funded by the Kiwanis Foundation through the United States Committee for UNICEF for which we are grateful. We are thankful for the survey teams for completing the fieldwork on time. We also acknowledge the valuable comments and suggestions of Habib Hammam, Akhil Iyer, Tania Barham, Ahmed Zahidi and Dr P.W. Dysinger.

\section{References}

1 Yemen General Grain Corporation and Ministry of Health. Yemen Arab Republic National Survey, 1979. Sana'a: Yemen General Grain Corporation and Ministry of Health, 1979.

2 Kristiannson B, Nasher A, Bagenholm G. Nutrition, Growth and Health among Pre-school Children in PDRY Yemen 1982-83. PDRY: Ministry of Health, Aden, 1983. 
3 Azizi F. Iodine Deficiency Disorders in the Republic of Yemen. Assignment Report No. WHO/EMORO/EM/NUT/ 106/E/R/12.91/30. Alexandria: Yemen: World Health Organization 1991.

4 Central Statistical Organisation. Statistical Year Book, Yemen. Sana'a: Al-thawra Newspaper Publishers, 1997.

5 UNICEF. The State of the World's Children. New York: Oxford University Press, 1998.

6 World Bank/Radda Barnen/UNICEF. Children and Women in Yemen, a Situation Analysis. Sana'a: UNICEF Yemen, 1998.

7 UNDP. Human Development Report. New York: Oxford University Press, 1999.

8 Zar JH. Biostatistical Analysis. Englewood Cliffs: Prentice Hall, 1984.

$9 \mathrm{WHO} / \mathrm{UNICEF} / \mathrm{IDDIDD}$. Indicators for Assessing Iodine Deficiency Disorders and their Control Through Salt Iodination. Report No. WHO/NUT/94.6. Geneva: World Health Organization, 1994.

10 Dunn JT, Crutchfield HE, Gutekunst R, Dunn AD. Two simple methods for measuring iodine in urine. Thyroid 1993; 3: $119-23$

11 Pardede LV, Hardjowasito W, Gross R, et al. Urinary iodine excretion is the most appropriate outcome indicator for iodine deficiency at field conditions at district level. J. Nutr. 1998; 128: 1122-6.
12 Kapil U, Saxena N, Ramachandran S, Balamurugan A, Nayar D, Prakash S. Assessment of iodine deficiency disorders using the 30-cluster approach in the national capital territory of Delhi. Ind. Pediatr. 1997; 33: 1013-16.

13 Palestinian Ministry of Health. Report on Iodine Deficiency Survey in West Bank and Gaza Strip. Palestine: Ministry of Health, 1997.

14 Zein AZ. Situation Analysis and Control Strategy for IDD in Yemen. UNICEF Yemen, 1993.

15 Office of the Attorney General. Law No. 32/1996 on Fortifying Food with Iodine. Yemen: Official Gazette, 1996.

$16 \mathrm{WHO} / \mathrm{UNICEF} / \mathrm{ICCIDD}$. IDD in the Middle East. IDD Newsletter 1993; 9: 13-17.

17 Ministry of Public Health/UNICEF. IDD Survey in Lebanon Lebanon: 1998

18 Ministry of Health/UNICEF/WHO. Monitoring Universal Salt Iodination in Oman. Oman: Muscat, 1997.

19 Suleimani R, Omar S, Al-Attas A. The prevalence of endemic goitre among school children and adolescents in Gizan, Saudi Arabia. Saud. Med. J. 1995; 16: 291-3.

20 International Council for Control of Iodine Deficiency Disorders, Charlottesville, U.S.A. Iodine-induced hyperthyroidism. IDD Newsletter 1998; 14: 9-11.

21 UNICEF. Salt Iodization Database. Health and Nutrition Section, UNICEF Yemen, 1999. 